\title{
Experimental Investigation on the Tissue Response Induced by Face-Lifting Mesh Suspension Thread in Rats
}

\author{
Jung Eun Kim, Yo Han Kim ${ }^{1}$, A Young Park, Ho Jung Lee, Jong Hun Lee \\ Department of Dermatology, Soonchunhyang University Cheonan Hospital, Soonchunhyang University College of Medicine, Cheonan, \\ ${ }^{1}$ Department of Plastic Surgery, Artinu Plastic Surgery Clinic, Hwaseong, ${ }^{2}$ Department of Plastic and Reconstructive Surgery, Eulji \\ General Hospital, Eulji University School of Medicine, Seoul, Korea
}

Background: Face-lifting procedures are often performed to hide the effects of aging. Thread-lifting, a minimally invasive technique for the correction of facial aging, has become increasingly popular, and various materials for the procedure have been developed. Objective: This study compared tissue responses to two types of threading sutures placed under rat skin: polypropylene (PP) monofilament mesh suspension thread (a novel face-lifting material) and polydioxanone (PDO) barbed thread. Methods: Eight rats each were assigned to the PP monofilament mesh suspension, PDO barbed thread, and control groups. Tissue reactions were evaluated 28 days after subcutaneous loading of the materials. Results: Significant increases in tensile strength and the mean area occupied by collagen fibers were evident in skin loaded with PDO barbed thread and PP monofilament mesh suspension thread compared to control skin $(p<0.05)$. Compared to sites loaded with PDO barbed thread, those loaded with PP monofilament mesh suspension thread showed a significant increase in the number of collagen fibers and a lower grade of inflammation $(p<0.05)$. Conclusion: PP monofilament mesh suspension thread has skin-rejuvenating effects comparable to those of PDO barbed thread, but induces a

Received May 27, 2019, Revised August 22, 2019, Accepted for publication September 18, 2019

Corresponding author: Jong Hun Lee, Department of Plastic and Reconstructive Surgery, Eulji General Hospital, Eulji University School of Medicine, 68 Hangeulbiseok-ro, Nowon-gu, Seoul 01830, Korea. Tel: 82-2-970-8255, Fax: 82-2-978-4772, E-mail: joaljh@eulji.ac.kr ORCID: https://orcid.org/0000-0001-6417-6986

This is an Open Access article distributed under the terms of the Creative Commons Attribution Non-Commercial License (http://creativecommons. org/licenses/by-nc/4.0) which permits unrestricted non-commercial use, distribution, and reproduction in any medium, provided the original work is properly cited.

Copyright (c) The Korean Dermatological Association and The Korean Society for Investigative Dermatology less severe inflammatory response. This indicates that it is a safe and effective material for use in thread-lifting procedures on aging skin. (Ann Dermatol 31(6) $645 \sim 653,2019$ )

\section{-Keywords-}

Face-lifting, Mesh suspension thread, Polydioxanone thread, Thread-lifting

\section{INTRODUCTION}

Facial aging is a natural biological process that leads to the thinning, loss of elasticity, and increased laxity of facial skin together with the formation of wrinkles and the atrophy of soft tissues. With aging, connections between muscle and other tissues become weaker, resulting in the gradual development of brow ptosis, orbital rim prominence, deepening of the nasolabial folds, sagging skin and jowl formation ${ }^{1-5}$. Surgical correction of these involutional signs of facial aging ${ }^{6,7}$ often yield dramatic improvements. However, there are risks associated with general anesthesia and potential perioperative complications, including hematoma, skin flap necrosis, scar formation, parotid fistulation, and facial nerve injury ${ }^{8,9}$. Thus, more durable and less invasive means of face-lifting have been sought ${ }^{10,11}$.

One such procedure is thread-lifting, which is now widely used for brow-, midface-, jowl-, and neck-lifting ${ }^{12,13}$. A specific type of suture material is required to provide sufficient traction/holding power and thus long-lasting effects. Thread-lifting is continuously evolving, including new thread materials and shapes (e.g., by changing the directions of the barbs) and modified fixation techniques. The ideal thread-lifting material induces a minimal inflammatory response and achieves excellent cosmetic results. 
Recently, a polypropylene (PP) monofilament mesh suspension thread composed of an implantable distal mesh and a barbed thread became available commercially ${ }^{14}$. We compared the tissue responses to two types of threading suture after subcutaneous loading under rat skin: PP monofilament mesh suspension thread and polydioxanone (PDO) barbed thread.

\section{MATERIALS AND METHODS}

\section{Animals and experimental groups}

Twenty-four healthy male SPF/VAF outbred Crl:CD1 (Sprague Dawley, SD) rats (6 weeks old; OrientBio, Seongnam, Korea, ANNEX I and II) were housed in our animal facility. After 9 days of acclimatization, they were allocated to groups of four, with each group housed together in a polycarbonate cage placed in a temperature- $\left(20^{\circ} \mathrm{C} \sim 25^{\circ} \mathrm{C}\right)$ and humidity- $(30 \% \sim 35 \%)$ controlled room. The light: dark cycle was 12 hours:12 hours and food and water were supplied ad libitum. Body weights were measured (average, 251.25 $\pm 11.09 \mathrm{~g}$; range, 235.0 271.0 g) 1 day before placement of the test material (Table 1, Fig. 1). All experimental procedures were conducted in accordance with the National Institute of Health's Guide for the Care and Use of Laboratory Animals (NIH publication no. 85-
23, reviewed in 1996). This study was approved by the Institutional Animal Care and Use Committee of Daegu Haany University, Gyeongsan, Korea (no. 88/2016). Then the 24 rats were divided into three groups of eight. Group A consisted of unloaded (control) rats, group $B$ of rats subcutaneously loaded with PDO barbed thread (MIRACU ${ }^{\mathrm{TM}}$; Dongbang Medical Co. Ltd., Seongnam, Korea), and group C of rats subcutaneously loaded with PP monofilament mesh suspension thread (RaiseMeUp ${ }^{\mathrm{TM}}$; Prestige Medicare Co. Ltd., Seongnam, Korea) (Fig. 2).

\section{Preparation of test materials}

PP monofilament mesh suspension thread and PDO barbed thread were supplied as complete kits, which were stored at room temperature with protection from light and moisture.

\section{Subcutaneous loading of test materials}

The two test materials were subcutaneously loaded using needle-type probes after the dorsal hair of the rats was clipped and the area sterilized with povidone iodine (BetadineTM; Korea Pharma Co., Hwaseong, Korea). During this procedure, the rats were placed under inhalation anesthesia with 3\% (v/v) isoflurane (Hana Pharm. Co., Hwaseong, Korea) in a mixture of $70 \% \mathrm{~N}_{2} \mathrm{O}$ and $28.5 \%$

Table 1. Experimental design used in this study

\begin{tabular}{|c|c|c|c|}
\hline & Group & Animal treatment & Animal No. \\
\hline Group A & Intact (control) & No loading & R01 R08 \\
\hline Group B & PDO barbed thread & Reference material, subcutaneously loaded & $R 09 \sim R 16$ \\
\hline Group C & PP monofilament mesh suspension thread & Test material, subcutaneously loaded & $\mathrm{R} 17 \sim \mathrm{R} 24$ \\
\hline
\end{tabular}

PDO: polydioxanone, PP: polypropylene, group A: unloaded (control), group B: subcutaneously loaded with PDO barbed thread $\left(\right.$ MIRACU $^{\mathrm{TM}}$ ), group C: subcutaneously loaded with PP monofilament mesh suspension thread (RaiseMeUp ${ }^{\mathrm{TM}}$ ).

Four weeks of observation

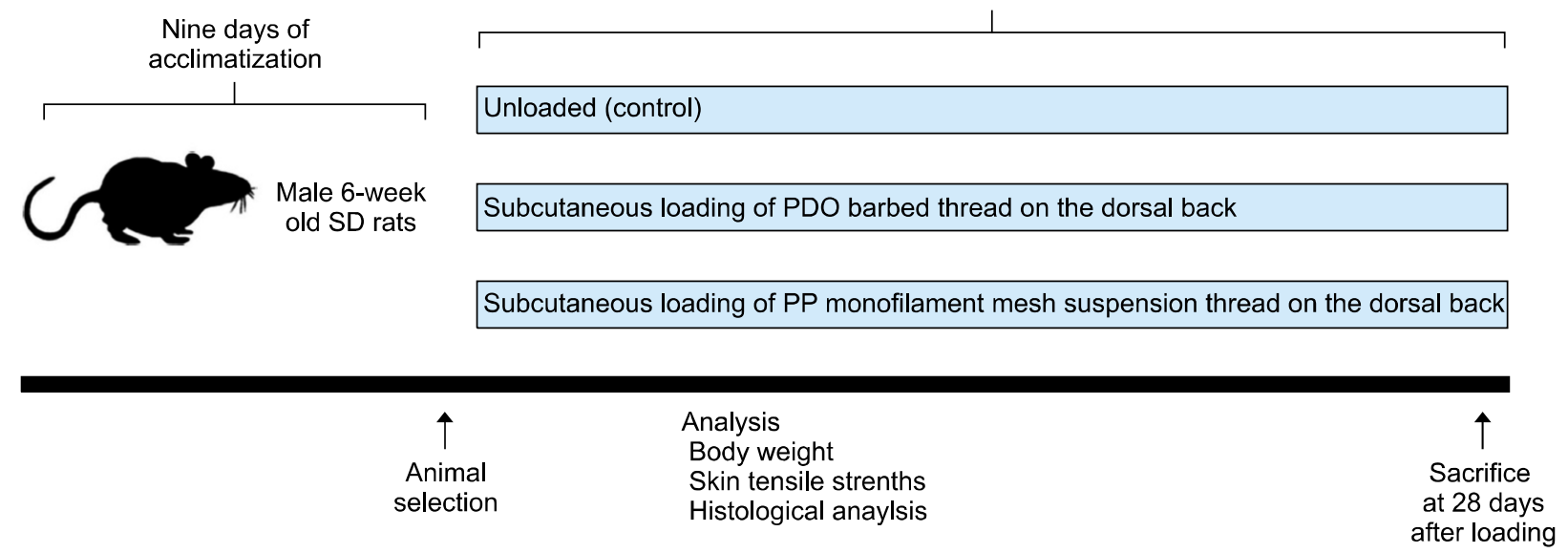

Fig. 1. Experimental design of the study. SD rats: Sprague Dawley rats, PDO: polydioxanone, PP: polypropylene. 


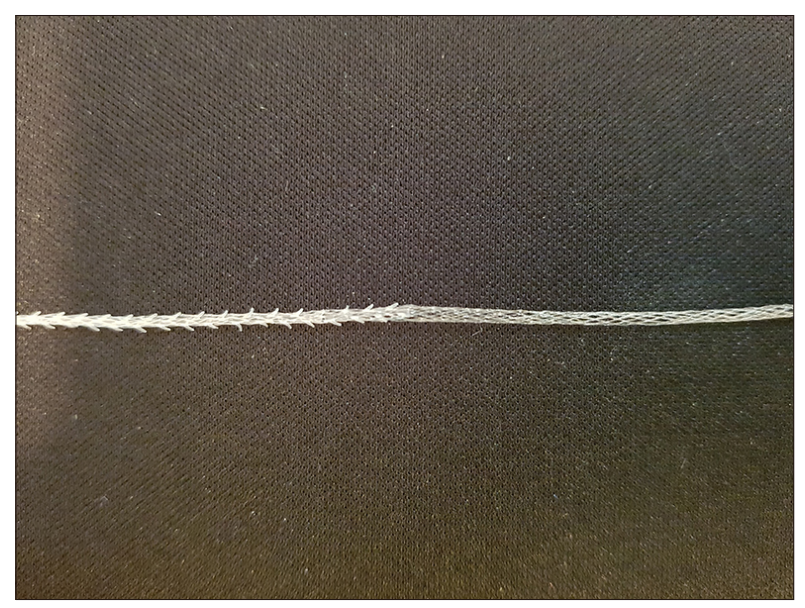

Fig. 2. Photograph of polypropylene monofilament mesh suspension thread (RaiseMeUp ${ }^{\mathrm{TM}}$; Prestige Medicare Co. Ltd., Seongnam, Korea).

$\mathrm{O}_{2}$ (both $\mathrm{v} / \mathrm{v}$ ), administered using a rodent inhalation anesthesia apparatus (Surgivet, Waukesha, WI, USA) and a rodent ventilator (model 687; Harvard Apparatus, Cambridge, UK). The test materials were loaded longitudinally, on the right and left sides of each rat, and then fixed to the loaded sites by skin sutures made with 3-0 black silk, with two ties per test material, at the cephalic and caudal sites. Control rats (group A) underwent hair clipping and skin sterilization with no material loading.

\section{Changes in body weight}

Body weights were measured at day -1 , day 0 (the day of subcutaneous loading) and days 7, 14, 21, and 28 after loading, using an automatic electronic balance (Precisa Instrument, Zurich, Switzerland). All animals were fasted overnight (for 18 hours; water was not restricted) prior to test material loading to reduce individual differences caused by feeding behavior.

\section{Gross inspection and skin tensile strength measurement}

The rats were sacrificed under inhalation anesthesia and squares of dorsal skin (from both the right and left loading sites) were inverted to observe the subcutaneous regions. Skin tensile strength was measured (in Newtons; N) using a computerized testing device (SV-H1000; Japan Instrumentation System Co., Tokyo, Japan). Equally sized squares from the right side of the dorsal skin, with (groups B, C) or without (group A) loaded test material, were sampled 28 days after subcutaneous loading. The tissue samples were fixed into the machines at two points (cephalic and caudal sites). Peak tensile loads were recorded as skin tensile strength apparent during a $10 \mathrm{~mm}$ expansion.
Table 2. Classification of inflammation grade

\begin{tabular}{|c|c|}
\hline Grade & Response \\
\hline 0 & No inflammatory response \\
\hline 1 & $\begin{array}{l}\text { Mild inflammatory response, with low cell density } \\
\text { present in up to } 25 \% \text { of the analyzed area }\end{array}$ \\
\hline 2 & $\begin{array}{l}\text { Moderate inflammatory response, with medium cell } \\
\text { density present in } 26 \% \sim 75 \% \text { of the analyzed area }\end{array}$ \\
\hline 3 & $\begin{array}{l}\text { Severe inflammatory response, with high cell density } \\
\text { present in more than } 75 \% \text { of the analyzed area }\end{array}$ \\
\hline
\end{tabular}

\section{Histopathology}

The dorsal skin on the left side (containing the test materials) was sampled 28 days after subcutaneous loading and fixed in $10 \%(\mathrm{v} / \mathrm{v})$ neutral buffered formalin (NBF) for 24 hours. Individual samples were trimmed and re-fixed in $10 \%(\mathrm{v} / \mathrm{v})$ NBF. After paraffin embedding, 3 to $4 \mu \mathrm{m}$-thick sections were obtained and stained with hematoxylin and eosin (H\&E) and Masson's trichrome (MT). The latter identifies collagen fibers. Mast cells were identified with toluidine blue (TB) stain ${ }^{15-18}$. An experienced pathologist observed the mounted slides under a light microscope (Model Eclipse 80i; Nikon, Tokyo, Japan) at $40 \times, 100 \times$, and $400 \times$ magnification. More detailed information was obtained by determining the mean diameters of the remnant-loaded test materials (in $\mu \mathrm{m}$ ), the amount of mast cell infiltration, the inflammatory response around the loaded test materials, and the percentage of tissue occupied by collagen fibers. The inflammatory response was graded according to the greater or lesser presence of inflammatory cells, principally lymphocytes and macrophages under $\mathrm{H} \& \mathrm{E}$ stain (Table 2). Microscopy-based counts from five highpower fields in skin regions with a predominance of inflammatory cells were averaged. The number of mast cells, averaged over eight high-power fields, was counted on TB-stained sections. The percentage of skin region occupied by collagen fiber (per square millimeter of dermis) was calculated from MT-stained sections.

Histomorphometric analyses were done using a computerassisted image-analysis program (iSolution FL ver. 9.1; IMT $i$-solution Inc., Vancouver, QU, Canada) as described previously ${ }^{15-18}$ but with a few modifications. One histological field running from the epidermis to the hypodermis in each section, from around the centrally located loading sites, and eight dorsal skin samples from each group, were histopathologically evaluated. At least five repeat measurements were conducted, whenever possible, on the same specimens to calculate mean histomorphometric values. The pathologist was blinded to the group. 


\section{Statistical analyses}

All numerical data are expressed as means \pm standard deviations. Multiple comparison tests were conducted. Homogeneity of variance was examined using Levene's test $^{19}$. If the result indicated no significant deviation, the data were analyzed using a one-way ANOVA followed by the least-significant difference multi-comparison test to identify pairs of groups that differed significantly. If the Levene test revealed a significant deviation from homogeneity, a non-parametric Kruskal-Wallis $\mathrm{H}$ test was conducted. If the latter revealed a significant difference, a Mann-Whitney $U$ test was performed ${ }^{20}$. The level of significance was set at $p<0.05$. All statistical analyses were conducted using IBM SPSS Statistics ver. 20.0 (IBM Corp., Armonk, NY, USA).

\section{RESULTS}

\section{Changes in body weight and weight gain}

Body weight gain during the 28 days was observed in the rats of all three groups. The differences $(p>0.05)$ in body weight or weight gain between rats in groups $B$ or $C$ and those in group A were not significant throughout the 28 days of the loading period (Table 3, Fig. 3).

\section{Gross findings and changes in skin tensile strength}

There were no serious gross findings in the loaded regions of group $\mathrm{B}$ and $\mathrm{C}$ rats compared to group $\mathrm{A}$ control rats, at least not macroscopically (Fig. 4). Significant $(p<0.05)$ increases in skin tensile strength were evident in groups $B$ and $\mathrm{C}$ compared to group $\mathrm{A}$, regardless of whether the test materials were intact or remnant (Fig. 5). However, there were no significant differences in the skin tensile strength between groups B and C ( $p>0.05)$. After removal of the remnant test materials, significant $(p<0.05)$ decreases in skin tensile strength were evident in both experimental groups compared to the similarly treated control group.

\section{Histolopathological findings}

\section{1) Remnant-loaded test materials}

The mean single-filament diameter of remnant material in group B rats was $586.25 \pm 26.25 \mu \mathrm{m}$, and the mean diameter of remnant bundles in group $C$ rats $574.77 \pm 31.6 \mu \mathrm{m}$. The bundles in group $C$ rats were composed of fibers of 12 subtypes, with a mean diameter of $120.77 \pm 6.25 \mu \mathrm{m}$ (Table 4, Fig. 6A). The two types of remnant material were observed in the respective rats 28 days after loading, in close proximity to the loading sites.

\section{2) Inflammatory response}

Inflammatory response grades were significantly $(p<0.05)$

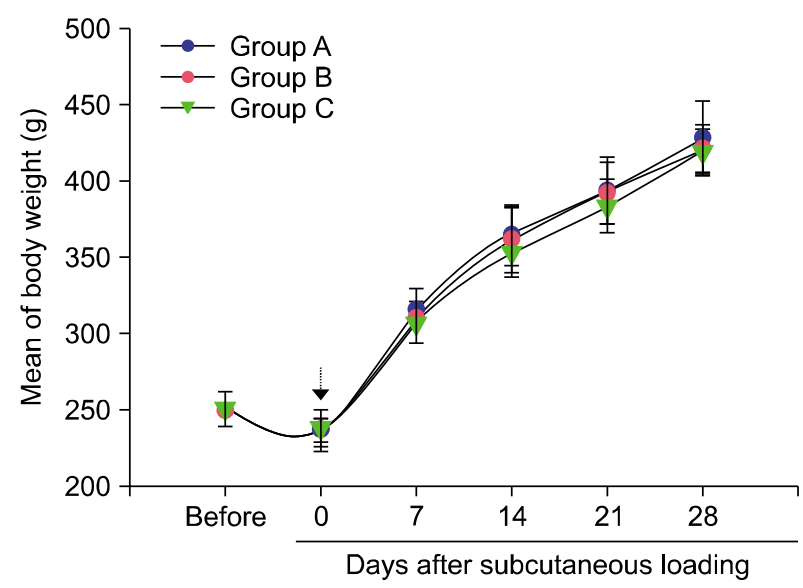

Fig. 3. Body weight changes. There were no significant changes in the body weights of rats in groups $B$ or $C$ compared to rats in group A throughout the 28-day loading period. Before: 1 day before subcutaneous loading. The rats were sacrificed on day 28 after loading. All animals were fasted overnight before subcutaneous loading (dotted arrow). Group A: unloaded (control), group B: subcutaneously loaded with polydioxanone barbed thread (MIRACU ${ }^{\mathrm{TM}}$ ), group C: subcutaneously loaded with polypropylene monofilament mesh suspension thread (RaiseMeUp ${ }^{T M}$ ).

Table 3. Body weight gains in intact rats and those loaded with test materials

\begin{tabular}{lccccc}
\hline \multirow{2}{*}{ Group } & \multicolumn{4}{c}{ Body weight on: } & \\
\cline { 2 - 5 } & $\begin{array}{c}1 \text { day before } \\
\text { subcutaneous loading }\end{array}$ & $\begin{array}{c}\text { Day of subcutaneous } \\
\text { loading [A]* }\end{array}$ & $\begin{array}{c}21 \text { days after } \\
\text { subcutaneous loading }\end{array}$ & $\begin{array}{c}28 \text { days after loading, } \\
\text { at sacrifice [B] }\end{array}$ & $\begin{array}{c}\text { Body weight } \\
\text { gain [B-A] }\end{array}$ \\
\hline $\begin{array}{l}\text { Group A } \\
\text { Subcutaneously loaded rats }\end{array}$ & $251.0 \pm 11.6$ & $238.8 \pm 11.9$ & $315.4 \pm 14.9$ & $394.3 \pm 21.9$ & $189.4 \pm 19.6$ \\
Group B & $250.8 \pm 11.6$ & $237.5 \pm 7.7$ & $392.6 \pm 20.1$ & $421.8 \pm 15.3$ & $184.3 \pm 18.6$ \\
Group C & $252.0 \pm 11.5$ & $237.6 \pm 13.7$ & $384.1 \pm 17.1$ & $419.3 \pm 14.3$ & $181.6 \pm 11.6$ \\
\hline
\end{tabular}

Values (g) are expressed as the mean \pm standard deviation from eight rats. Group A: unloaded (control), group B: subcutaneously loaded with polydioxanone barbed thread $\left(\right.$ MIRACU $\left.^{\mathrm{TM}}\right)$, group C: subcutaneously loaded with polypropylene monofilament mesh suspension thread (RaiseMeUp ${ }^{\mathrm{TM}}$ ), *All animals were fasted overnight ( $\sim 18$ hours; water was not restricted). 

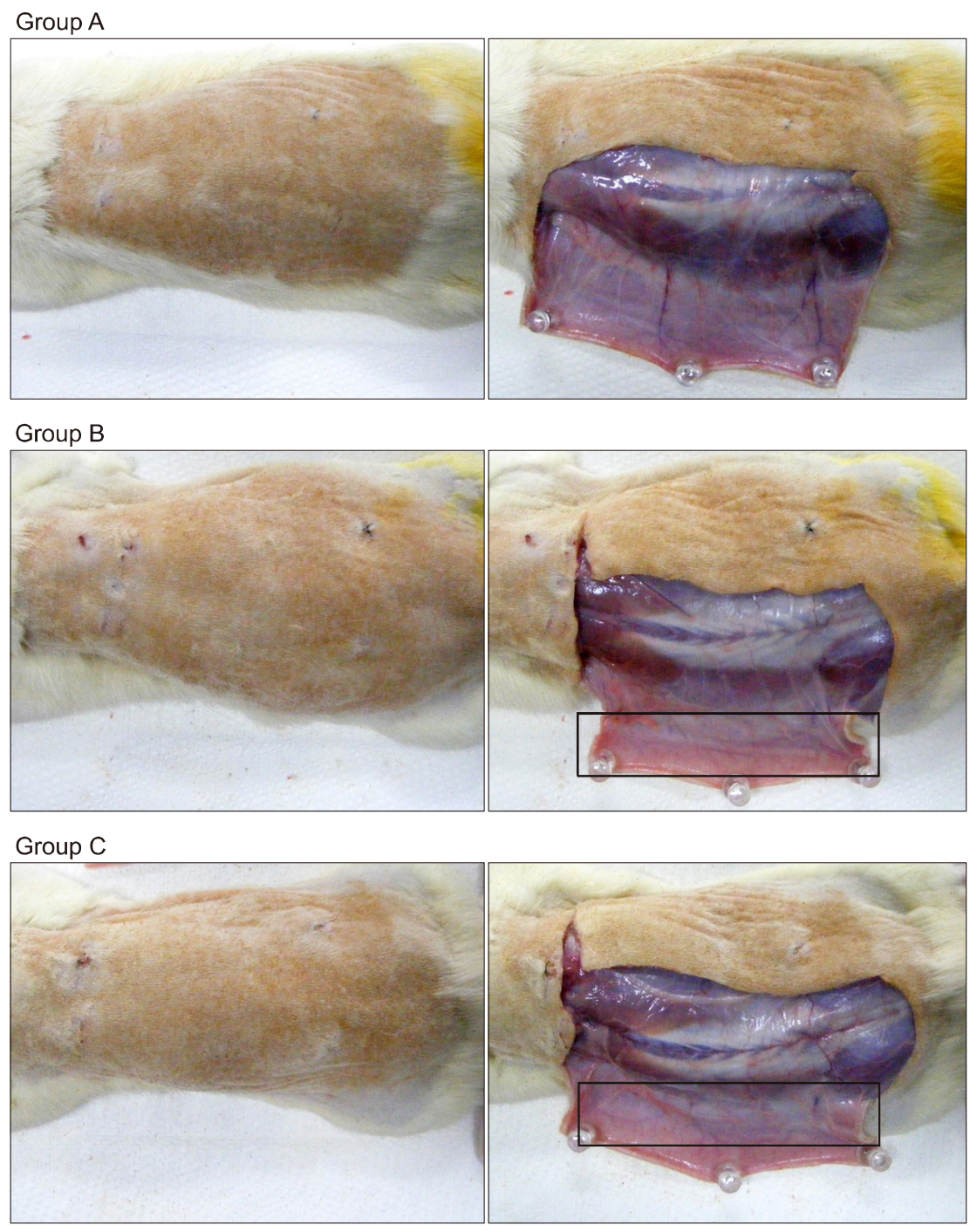

Fig. 4. Representative gross findings. There were no serious gross findings around sites loaded with polydioxanone (PDO) barbed thread or polypropylene (PP) monofilament mesh suspension thread compared to control sites. Squares indicate remnant loaded materials. Group A: unloaded (control), group B: subcutaneously loaded with PDO barbed thread (MIRACU ${ }^{\mathrm{TM}}$ ), group C: subcutaneously loaded with PP monofilament mesh suspension thread (RaiseMeUp ${ }^{\mathrm{TM}}$ ). higher around the loaded sites in group B than in those of either group $C$ or group $A$ (Table 4). Most of the infiltrated cells were lymphocytes. (Fig. 6A) Whereas the three groups did not significantly differ $(p>0.05)$ with respect to the mean number of mast cells (Table 4, Fig. 6B).

\section{3) Area of collagen fiber}

Significant increases in the mean area occupied by collagen fibers were evident in the skin of group $B$ and $C$ rats compared to the skin of group A rats (Table 4). Moreover, compared to the loaded sites in group $B$, those in group $C$ were characterized by a significant increase in collagen fibers $(p<0.05)$ (Fig. 6C).

\section{DISCUSSION}

In face-lift procedures, the use of less invasive techniques with minimal risk and short recovery times, such as the
S-lift, delta-lift, lower superficial musculoaponeurotic system (SMAS) lift, and more recently, percutaneous suture suspension, are in increasing demand. Percutaneous suspension sutures afford gentle rejuvenation of the face, improving folding, soft-tissue ptosis, and skin redundancy ${ }^{21}$. Barbed sutures were originally developed in 1992 by Ruff and independently by Sulamanidze et al. in $1996^{1}$. Wu ${ }^{22}$ used another type of barbed suture, one that effectively suspends sagging tissue from the stable tissue of the temporal scalp. Isse developed the Isse endo-progressive face-lift suture, made of PP filaments with unidirectional barbs that become anchored to the temporalis fascia. Contour threads consist of $25 \mathrm{~cm}$ lengths of 2-0 PP suture material including a central $10 \mathrm{~cm}$ segment that contains 50 unidirectional, helicoidally configured barbs. The silhouette lift suture is a nonabsorbable PP 3-0 suture featuring small knots and flexible cones ${ }^{23}$.

The many types of threads that are currently available 
have been developed using different materials and different synthetic cog structures. The latter can be generally classified into three types: non-barbed sutures, bidirectionally barbed non-anchored sutures, and unidirectionally barbed anchored sutures ${ }^{24}$. Recently, a PP mesh suspension thread featuring an implantable distal mesh and a barbed thread was introduced. PP meshes are used in many fields of surgery besides face-lifts. For example, the use of a mesh supporting system in a double-skin technique for mammoplasty and in the closure of the abdominal wall in numerous other operations has been reported ${ }^{25,26}$. The advantages of PP monofilament mesh suspension thread include increased tensile strength and placement in the sub-SMAS plane. The tensile strength (apart from that

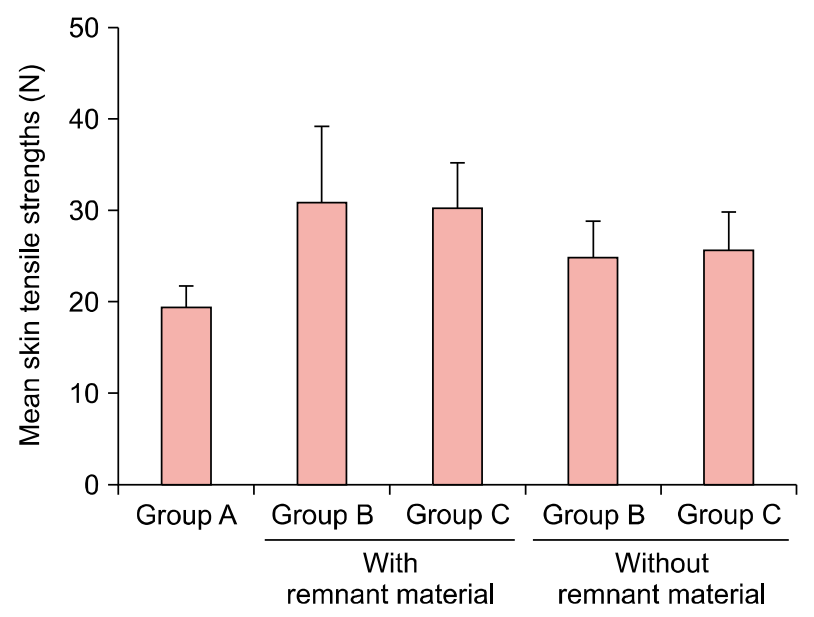

Fig. 5. Tensile strength on the dorsal skin. Significant increases in skin tensile strength were determined in groups B and C compared to group $A$, with and without remnant loaded thread. Values are expressed as the mean \pm standard deviation of the data from eight rats. Group A: unloaded (control), group B: subcutaneously loaded with polydioxanone barbed thread (MIRACU ${ }^{\mathrm{TM}}$ ), group C: subcutaneously loaded with polypropylene monofilament mesh suspension thread (RaiseMeUp ${ }^{\mathrm{TM}}$ ). afforded by the cogs) is increased by the distal mesh while the pore size $(<1 \mathrm{~mm})$ of the mesh results in less-extensive scar formation. Furthermore, a separate mesh segment is used for fixation to the deep temporal fascia, which increases both thread stability and the longevity of the lifting effect ${ }^{27}$. Kwon et al. ${ }^{28}$ demonstrated that a PP mesh had sufficient mechanical strength and stretching force for use in brow suspension. Pak et al. ${ }^{25}$ also used PP mesh in nasolabial folds and reported that there were no serious adverse effects in treated patients. However, as with every newly developed procedure and the associated materials, there are benefits and drawbacks that must be carefully evaluated.

In the present work, significant increases $(p<0.05)$ in skin tensile strength and the mean area occupied by collagen fibers were evident 28 days after subcutaneous loading with PP monofilament mesh suspension thread and PDO barbed thread, compared to control rats. In addition, significant increases in collagen fibers were seen in the sites loaded with PP monofilament mesh suspension thread vs. PDO barbed thread $(p<0.05)$. However, the difference in tensile strength between skin loaded with PDO barbed thread and PP monofilament mesh suspension thread was not significant $(p>0.05)$. Increases in tensile strength and collagen fibers have been associated with skin rejuvenation $^{17,24,27,29-33}$. Our results suggest that the two test materials induce similarly potent collagen deposition and increases in skin tensile strength, both of which are closely related to skin rejuvenation.

Materials appropriate for the treatment of skin aging should remain at the loading site and should not cause serious local irritation ${ }^{15,34,35}$. In this study, compared to control skin, sites loaded with PDO barbed thread exhibited a significantly $(p<0.05)$ more intense inflammatory response, whereas this was not the case in sites loaded with PP monofilament mesh suspension thread. In their study of meshes used to repair abdominal wall incisional defects,

Table 4. Histomorphometric analysis of regions around subcutaneously loaded sites

\begin{tabular}{lccc}
\multicolumn{1}{c}{ Item } & Group A & \multicolumn{2}{c}{ Subcutaneously loaded rats } \\
\cline { 3 - 3 } & & Group B & Group C \\
\hline Remnant material diameter $(\mu \mathrm{m})$ & & $586.3 \pm 26.3$ & $574.8 \pm 31.6$ \\
$\quad$ Bundles & - & - & $120.8 \pm 6.3$ \\
$\quad$ Fiber subtypes & $1.0 \pm 0.0$ & $2.1 \pm 1.0$ & $1.3 \pm 0.5$ \\
Grade of inflammatory response & $11.8 \pm 2.7$ & $12.4 \pm 2.7$ & $11.2 \pm 2.6$ \\
Mast cells (count/high-power field) & $59.4 \pm 3.0$ & $81.3 \pm 7.5$ & $100.4 \pm 8.6$ \\
Collagen fibers (\%/mm ${ }^{2}$ dermis) & & \\
\hline
\end{tabular}

Values are expressed as the mean \pm standard deviation from eight rats. Group A: unloaded (control), group B: subcutaneously loaded with polydioxanone barbed thread (MIRACU ${ }^{\mathrm{TM}}$ ), group C: subcutaneously loaded with polypropylene monofilament mesh suspension thread (RaiseMeUp ${ }^{\mathrm{TM}}$ ). 


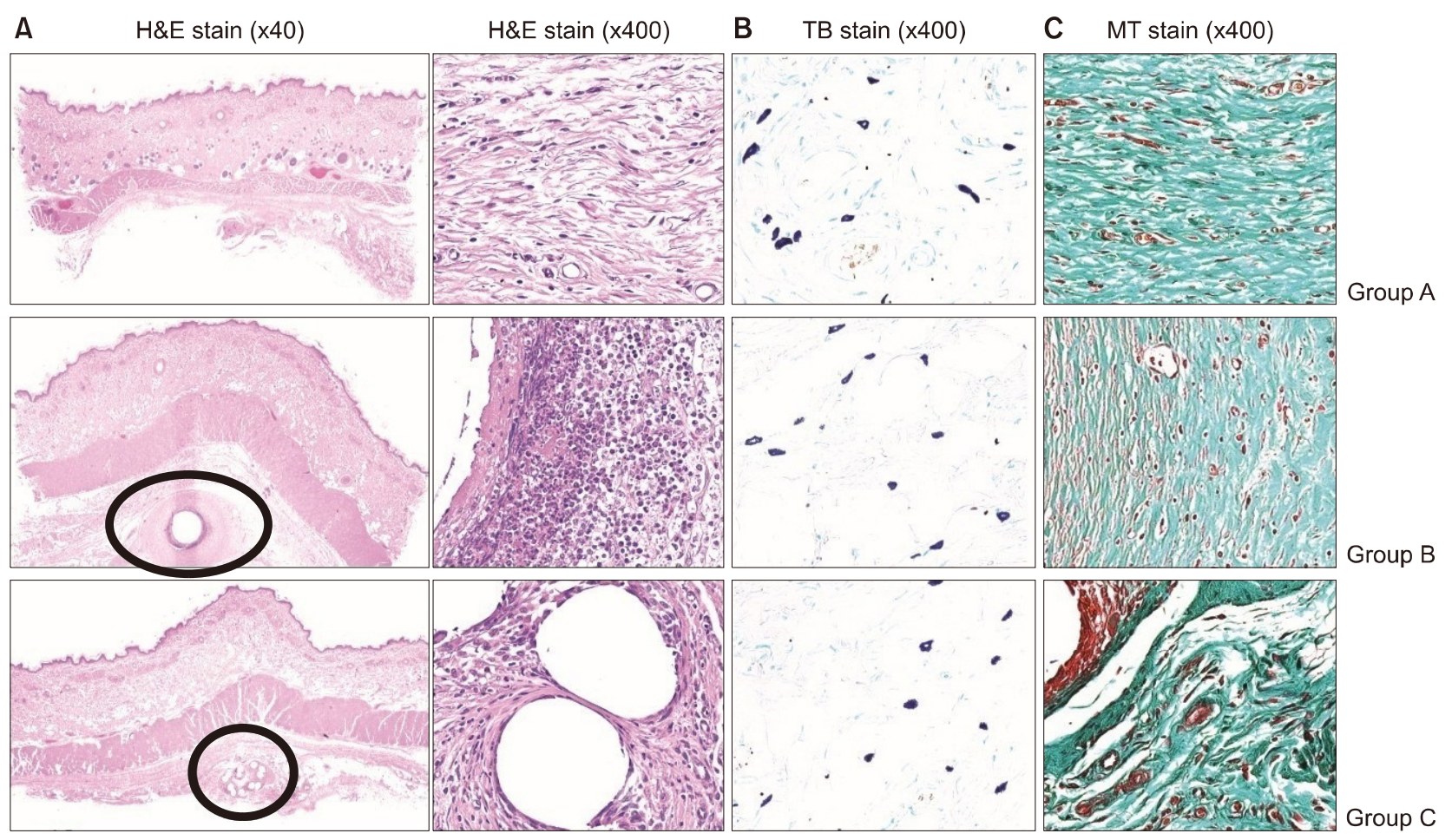

Fig. 6. Histological profiles of dorsal skin tissues around loading sites. Based on measurements from the hematoxylin and eosin (H\&E) stained sections (A), the mean diameter of the remnant material in group B was $586.25 \pm 26.25 \mu \mathrm{m}$, and the mean diameter of the remnant bundles in group $C$ was $574.77 \pm 31.60 \mu \mathrm{m}$. Bundles with a mean diameter of $120.77 \pm 6.25 \mu \mathrm{m}$ were detected 28 days after loading and were well localized to the loading sites. The mean inflammatory cell grade around loading sites was significantly higher in group B than in group A rats. On the toluidine blue (TB) stained sections (B), the mast cell infiltration around the loaded regions of the dorsal skin did not significantly differ between groups B and C and control group A rats. In the Masson's trichrome (MT) stained sections (C), significant increases in collagen fibers were evident in group $C$ compared to either group $A$ or group $B(p<0.05)$.

Pereira-Lucena et al. ${ }^{36}$ suggested that the absorbable materials in composite meshes prolong the inflammatory tissue reaction and that an intense inflammatory reaction might reduce tissue maturation and collagen deposition. Pascual et al. $^{37}$ also demonstrated that the use of meshes containing absorbable biological materials could increase the production of inflammatory mediators. Maeda et al. ${ }^{38}$ compared four different types of mesh: high-density PP, low-density PP, PP mesh encapsulated with oxidized cellulose-coated PDO, and expanded polytetrafluoroethylene. On postoperative day 28, the inflammatory scores of the low-density PP group were lower than those of all other groups $^{38}$. Our work also suggests that the use of absorbable biological materials, such as PDO, can prolong the inflammatory tissue reaction compared to PP. Long-term safety is the another important concern in the use of non-absorbable threads for aesthetic purposes. However, recent studies using PP monofilament suspension thread reported no major side effects at 6 or 12 months ${ }^{14,27}$. Mutaf $^{39}$ also reported the PP mesh lifting in the brow did not induce a foreign-body reaction during the 6 months to
4 years of follow-up. A study of 350 patients who underwent an Aptos procedure using PP barbed monofilament also reported no major complication over a 43-month period $^{12}$.

Overall, compared to PDO barbed thread, PP monofilament mesh suspension thread resulted in better collagen deposition while affording comparable skin tensile strength. The PP monofilament mesh suspension thread was also well preserved and remained at the loading site, where at 28 days it was associated with a less inflammatory response than seen at sites loaded with PDO barbed thread. Thus, PP monofilament mesh suspension thread may be a safe and effective thread-lifting material for the treatment of aging skin.

This study had several limitations, including the small number of animals in each group and the relatively short follow-up period. In addition, because we compared PP monofilament mesh suspension with PDO barbed thread rather than traditional PP thread, whether the difference in efficacy and safety were due to the PP material itself or to the newly developed implantable mesh could not be 
determined. Further work is needed to evaluate the longer-term efficacy and safety of PP monofilament mesh suspensions in human facial skin.

\section{ACKNOWLEDGMENT}

This work was supported by the National Research Foundation of Korea (grant no. NRF-2018R1C1B5042271) and the Soonchunhyang University Research Fund. This work was also (partly) supported by the Bio-Meditech Regional Innovation Center at Eulji University, under the Regional Innovation Center Program (2016-02-01) of Ministry Of Trade, Industry and Energy.

\section{CONFLICTS OF INTEREST}

The authors have nothing to disclose.

\section{ORCID}

Jung Eun Kim, https://orcid.org/0000-0002-8399-8456

Yo Han Kim, https://orcid.org/0000-0001-7335-430X

A Young Park, https://orcid.org/0000-0002-9775-0654

Ho Jung Lee, https://orcid.org/0000-0001-9674-6429

Jong Hun Lee, https://orcid.org/0000-0001-6417-6986

\section{REFERENCES}

1. Sulamanidze MA, Fournier PF, Paikidze TG, Sulamanidze GM. Removal of facial soft tissue ptosis with special threads. Dermatol Surg 2002;28:367-371.

2. Nkengne A, Bertin C. Aging and facial changes--documenting clinical signs, part 1 : clinical changes of the aging face. Skinmed 2013;11:281-286.

3. Kazinnikova OG, Adamian AA. Age-specific changes in facial and cervical tissues: a review. Ann Plast Recontr Aesthetic Surg 2000;1:52-61.

4. Mitz V, Peyronie M. The superficial musculo-aponeurotic system (SMAS) in the parotid and cheek area. Plast Reconstr Surg 1976;58:80-88.

5. Owsley JQ. Lifting the malar fat pad for correction of prominent nasolabial folds. Plast Reconstr Surg 1993;91:463474; discussion 475-466.

6. Kang MS, Shin JS, Nam SM, Park ES. Evaluation of elastic lift for facial rejuvenation. Arch Aesthetic Plast Surg 2016; 22:20-27.

7. Paul MD, Calvert JW, Evans GR. The evolution of the midface lift in aesthetic plastic surgery. Plast Reconstr Surg 2006; 117:1809-1827.

8. Kaminer MS, Bogart M, Choi C, Wee SA. Long-term efficacy of anchored barbed sutures in the face and neck. Dermatol Surg 2008;34:1041-1047.

9. Derby BM, Codner MA. Evidence-based medicine: face lift.
Plast Reconstr Surg 2017;139:151e-167e.

10. Sapountzis S, Kim JH, Li TS, Rashid A, Cruz PC, Hwang YS. Successful treatment of thread-lifting complication from APTOS sutures using a simple MACS lift and fat grafting. Aesthetic Plast Surg 2012;36:1307-1310.

11. Park TH, Seo SW, Whang KW. Facial rejuvenation with fine-barbed threads: the simple Miz lift. Aesthetic Plast Surg 2014;38:69-74.

12. Lycka B, Bazan C, Poletti E, Treen B. The emerging technique of the antiptosis subdermal suspension thread. Dermatol Surg 2004;30:41-44; discussion 44.

13. Abraham RF, DeFatta RJ, Williams EF 3rd. Thread-lift for facial rejuvenation: assessment of long-term results. Arch Facial Plast Surg 2009;11:178-183.

14. Han SE, Go JY, Pyon JK, Oh KS. A prospective evaluation of outcomes for midface rejuvenation with mesh suspension thread: "REEBORN lift". J Cosmet Dermatol 2016;15:254259.

15. Lee HS, Cho HR, Yang KJ, Shin HD, Park BR, Jang HJ, et al. Local irritation test of 3 types of $\beta$-glucan after subcutaneous injection in rats. Lab Anim Res 2006;22:339-342.

16. Drynda A, Seibt J, Hassel T, Bach FW, Peuster M. Biocompatibility of fluoride-coated magnesium-calcium alloys with optimized degradation kinetics in a subcutaneous mouse model. J Biomed Mater Res A 2013;101:33-43.

17. Kim $\mathrm{KH}$, Park SJ, Lee YJ, Lee JE, Song $\mathrm{CH}$, Choi $\mathrm{SH}$, et al. Inhibition of UVB-induced skin damage by exopolymers from Aureobasidium pullulans SM-2001 in hairless mice. Basic Clin Pharmacol Toxicol 2015;116:73-86.

18. Kim CG, Kang M, Lee Y-H, Min WG, Kim YH, Kang SJ, et al. Bathing effects of various seawaters on allergic (atopic) dermatitis-like skin lesions induced by 2,4-dinitrochlorobenzene in hairless mice. Evid-Based Complement Altern Med 2015;2015:179185.

19. Levene A. Pathological factors influencing excision of tumours in the head and neck. part I. Clin Otolaryngol Allied Sci 1981;6:145-151.

20. Ludbrook J. Update: microcomputer statistics packages. a personal view. Clin Exp Pharmacol Physiol 1997;24:294-296.

21. Gamboa GM, Vasconez LO. Suture suspension technique for midface and neck rejuvenation. Ann Plast Surg 2009;62: 478-481.

22. Wu WT. Barbed sutures in facial rejuvenation. Aesthet Surg J 2004;24:582-587.

23. Maschio F, Lazzaro L, Pizzamiglio R, Perego F, De Biasio F, Parodi PC. Suspension sutures in facial reconstruction: surgical techniques and medium-term outcomes. J Craniofac Surg 2013;24:e31-e33.

24. Shiffman MA, Mirrafati S, Lam SM, Cueteaux CG. Simplified facial rejuvenation. Berlin: Springer-Verlag, 2008. p. 257.

25. Pak CS, Chang LS, Lee $\mathrm{H}$, Jeong JH, Jeong J, Yoon ES, et al. A multicenter noncomparative clinical study on midface rejuvenation using a nonabsorbable polypropylene mesh: evaluation of efficacy and safety. Arch Plast Surg 2015;42: 572-579.

26. Moscona RA, Ramon Y, Toledano H, Barzilay G. Use of 
synthetic mesh for the entire abdominal wall after TRAM flap transfer. Plast Reconstr Surg 1998;101:706-710; discussion 711-702.

27. Sapountzis S, Nikkhah D, Kim JH, Seo JD. Novel polypropylene barbed threads for midface lift-“REEBORN Lifting". Plast Reconstr Surg Glob Open 2014;2:e250.

28. Kwon KA, Shipley RJ, Edirisinghe M, Ezra DG, Rose GE, Rayment AW, et al. Microstructure and mechanical properties of synthetic brow-suspension materials. Mater Sci Eng C 2014;35:220-230.

29. Fisher GJ, Varani J, Voorhees JJ. Looking older: fibroblast collapse and therapeutic implications. Arch Dermatol 2008; 144:666-672.

30. Quan T, Shao Y, He T, Voorhees JJ, Fisher GJ. Reduced expression of connective tissue growth factor (CTGF/CCN2) mediates collagen loss in chronologically aged human skin. J Invest Dermatol 2010;130:415-424.

31. Treiber N, Maity $P$, Singh K, Ferchiu F, Wlaschek $M$, Scharffetter-Kochanek K. The role of manganese superoxide dismutase in skin aging. Dermatoendocrinol 2012;4:232235.

32. Egbert $M$, Ruetze $M$, Sattler $M$, Wenck $H$, Gallinat $S$, Lucius $\mathrm{R}$, et al. The matricellular protein periostin contributes to proper collagen function and is downregulated during skin aging. J Dermatol Sci 2014;73:40-48.

33. Argyropoulos AJ, Robichaud P, Balimunkwe RM, Fisher GJ, Hammerberg $C$, Yan $Y$, et al. Alterations of dermal connective tissue collagen in diabetes: molecular basis of aged- appearing skin. PLoS One 2016;11:e0153806.

34. Chang L, Liu XL, Di Fan D, Miao YQ, Zhang H, Ma HP, et al. The efficiency of magnetic hyperthermia and in vivo histocompatibility for human-like collagen protein-coated magnetic nanoparticles. Int J Nanomedicine 2016;11:11751185.

35. van Essen TH, van Zijl L, Possemiers T, Mulder AA, Zwart $\mathrm{SJ}$, Chou $\mathrm{CH}$, et al. Biocompatibility of a fish scale-derived artificial cornea: cytotoxicity, cellular adhesion and phenotype, and in vivo immunogenicity. Biomaterials 2016;81: 36-45.

36. Pereira-Lucena CG, Artigiani Neto $R$, de Rezende DT, Lopes-Filho Gde J, Matos D, Linhares MM. Early and late postoperative inflammatory and collagen deposition responses in three different meshes: an experimental study in rats. Hernia 2014;18:563-570.

37. Pascual G, Rodríguez M, Sotomayor S, Pérez-Köhler B, Bellón JM. Inflammatory reaction and neotissue maturation in the early host tissue incorporation of polypropylene prostheses. Hernia 2012;16:697-707.

38. Maeda CT, Artigani Neto R, Lopes-Filho GJ, Linhares MM. Experimental study of inflammatory response and collagen morphometry with different types of meshes. Hernia 2016; 20:859-867.

39. Mutaf M. Mesh lift: a new procedure for long-lasting results in brow lift surgery. Plast Reconstr Surg 2005;116:14901499; discussion 1500-1501. 